Language Related Research

E-ISSN: 2383-0816

https://lrr.modares.ac.ir

https://doi.org/10.21859/LRR.11.5.227

Vol. 11, No. 5

pp. 227-252

November \&

December

2020

\title{
Integrating Culture into Teaching EFL in General Education: A Context of Vietnam
}

\author{
Chau Thi Hoang Hoa ${ }^{1}$ iD
}

\begin{abstract}
This action research study aims to test the feasibility of applying an intercultural language learning and teaching model (IcLLT) to teaching EFL in general education in Vietnam through teachers' and students' responses to two trial lessons. The IcLLT model of "construction", "connection", "interaction", "reflection", and "extension" is developed to foster students' intercultural competence by invoking their engagement in social interaction and critical cultural reflection. As shown in observations and students' evaluation sheets, the intercultural language activities in IcLLT lessons could engage the students in activating prior knowledge, comparing culture, talking about cultural issues, and participating in intercultural communication. However, they were not able to reflect on their intercultural perspectives in oral interaction as much as in their writing. In parallel, the teacher agreed that the activities requiring students' reflection were most challenging and the other three steps of "construction", "connection", "interaction" could be conducted in relevance to three-stage Communicative Language Teaching (CLT) skill lessons of Pre-While-Post. The IcLLT is applicable to teach integrated skill CLT lessons with culture-specific input if intercultural objectives are added and relevant intercultural language activities with more focus on students' intercultural interactions and critical reflection are conducted. Hence, IcLLT could be recommended as a supplementary approach to integrating culture into EFL teaching to build students' intercultural communicative competence, which is considered a critical part of the new educational reform in general education in Vietnam.
\end{abstract}

Keywords: IcLLT model, intercultural competence, intercultural communication, intercultural teaching, teaching EFL in general education

1. PhD, International Collabouration Office, Tra Vinh University, Tra Vinh, Vietnam; Email: cthhoa@tvu.edu.vn ; ORCID ID: https://orcid.org/000000257389147 


\section{Introduction}

In response to regional and global integration, intercultural integration is an essential part of teaching English as a foreign language (EFL) in general education in Vietnam. Vietnamese language-in-education policy has focused on developing intercultural competence (IC) for the students of this level. As a part of educational reform, the change in curriculum in teaching EFL is noticeable, particularly with the inclusion of intercultural objectives and the inclusion of intercultural input of a variety of cultures besides those of English-speaking countries (Hoang, 2016). Evaluating intercultural content in the pilot coursebook of grade 10, volume 1, Lai (2016) found that the proportion of home, target, and international culture is $51 \%$, $31 \%$, and $18 \%$ respectively. The cultures of ASEAN and Asian countries, namely Singapore, Malaysia, China, Thailand, South Korea, and Japan were included in a new EFL coursebook series (Hoang, 2018). The cultural content about these cultures is presented in a separate lesson, entitled "Communication and Culture", in tandem with language skill lessons in each unit. Given these points, the integration of culture in EFL teaching has been recognized at the macro level, with evidence of intercultural aims in the curriculum and the inclusion of intercultural content in the pilot coursebooks.

However, the practice of teachers in terms of intercultural teaching is not comprehensive enough to develop learners' IC or intercultural communicative competence (ICC). Theoretically, to the advocates of intercultural education (Byram, 1997; Crozet et al., 1999; Deardorff, 2006; Liddicoat, 2002; Liddicoat \& Scarino, 2013; Newton et al., 2010; Newton, 2016), IC had its own dimensions and developmental framework, so it could not be an incidental outcome of EFL teaching and the passive transmission of intercultural knowledge is not sufficient for IC formation and development. In pre-action research studies (Chau \& Truong, 2019), it was confirmed that the practice of EFL teachers did not observe "true" intercultural education theory. Teachers rarely conducted intercultural teaching activities to build students' intercultural attitudes and skills (Chau \& Truong, 2018) and their teaching practice was teacher-centered, knowledge-based, and coursebook-driven (Chau \& Truong, 2019). According to the Ministry of Education and Training (MOET) of Vietnam, CLT is considered the dominating EFL teaching method in general education (MOET, 2018), so the focus on communicative competence is explainable. Therefore, this is why integrating culture into teaching EFL requires an additional teaching approach, an intercultural language learning 
and teaching (IcLLT) approach to supplement CLT to support the attainment of the intercultural objectives as stated by $\operatorname{MOET}(2012,2018)$. This research aims to develop and explore the implementability of the IcLLT model to integrate culture into teaching EFL in general education in Vietnam through participating teacher's and students' responses to two trial lessons.

\section{Review of the Literature}

This part reviews the literature on culture, IC frameworks, intercultural language teaching approach in terms of principles, strategies, and suggestions for modifying EFL lessons and related studies in the field.

\subsection{Culture and IC Definitions}

There is no consensus in defining culture because it is viewed differently from field to field. From a dynamic view of culture, Liddicoat (1997) argued that culture is not only facts and artifacts or information and things, but also actions and understanding. Liddicoat et al. (2003, p. 45) defined culture as "a complex system of concepts, attitudes, values, beliefs, conventions, behaviors, practices, rituals, and lifestyle of the people who make up a cultural group, as well as the artifacts they produce and the institutions they create". Supporting Liddicoat et al.'s (2003) view of culture, Browett (2003) and Sewell (2005) agreed that culture is dynamic and ever-changing, and so are practices, behaviors, beliefs, values of cultural groups of people. This definition of culture does not convey the relationship between language and culture, but it has pedagogical meaning for reaching a relative degree of dynamicity and clarity of culture constitution. Regarding intercultural language education, culture or cultural input is recognized as culture-implicit and cultureexplicit or culture-specific and culture-general respectively (Dinh, 2016; Paige et al., 2003). If the input is tied to (a) specific cultural group or groups, it is specified as culture-explicit. If the input is general or unidentifiable to any group(s) of culture is marked as culture-implicit.

Defining cultural competence and IC depends on how we define culture. Fantini et al. (2001) made a distinction between cultural competence and IC. Cultural competence is "language-culture ability individuals develop for use in their native 
societies" (p. 4). This ability refers to an "acceptable" and "intelligible" performance within one's society. On the other hand, IC denotes the "multiple abilities that allow one to interact "effectively" and "appropriately" across cultures" (p. 8). Based on Fantini et al. (2001), IC comprises the competence in both the home and other cultures. IC, hence, is defined as the ability to communicate effectively and appropriately within and across cultural and linguistic backgrounds in one's native language.

\subsection{IC and ICC Frameworks}

Two major trends popularly accepted in IC research are the distinction and alternation between IC and ICC. Byram et al. (2002) made a clear distinction between IC and ICC. ICC refers to an "ability to ensure a shared understanding by people of different social identities, and the ability to interact with people as complex human beings with multiple identities and their own individuality" (Byram et al., 2002, p. 10). IC denotes the ability to mediate between cultures using one's own language and ICC using a foreign language. In a slightly different way, Fantini (2000, 2006) agreed that ICC and IC were two distinctive terms but could be used alternatively in many contexts. In details, ICC includes multiple constituents: (1) a variety of traits and characteristics, (2) three areas or domains, (3) four dimensions, (4) proficiency in the host language, and (5) varying levels of attainment throughout a longitudinal and developmental process (Fantini, 2000). The four IC dimensions are (1) knowledge, (2) attitudes, (3) skills, and (4) awareness, which evolve in a developing and continuous procedure, known as A + ASK quartet (Figure 1).

\section{Figure 1}

The Framework of Intercultural Communicative Competence (Fantini, 2000)

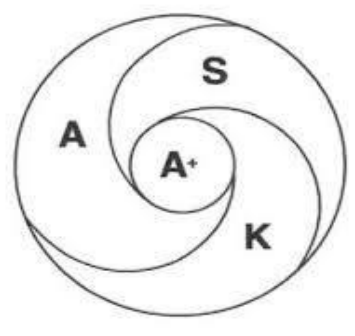


The developmental framework of IC in four areas regulates the choice and design of intercultural language activities and intercultural objectives in the intercultural language learning and teaching model (IcLLT) with principles and strategies described below.

\subsection{The Framework for ICLLT}

The IcLLT model and its principles and strategies are constructed in light of intercultural communicative language learning and teaching (Liddicoat et al., 2003; Liddicoat \& Scarino, 2013; Newton et al., 2010; Newton, 2016).

Liddicoat et al. (2003) and Liddicoat and Scarino (2013) proposed five principles for Intercultural Language Learning (IcLL) of "active construction", "making connections", "social interaction", "reflection, and "responsibility". The "active construction" involves meaningful construction of knowledge within a sociocultural context to enable learners to develop a personal and intercultural space from their own views. The "making connections" relates to engaging in constructive analysis of linguistic and cultural similarities and differences between home and target language and culture. The "social interaction" is referred to as communicating across linguistic and cultural boundaries and engaging with new conceptual systems through language. The "reflection" indicates the underlying process of conscious awareness and consideration. Finally, the "responsibility" inspires learners to involve themselves in successful communication across language and culture to develop intercultural awareness. The five IcLL principles represent a complete model or a holistic approach for intercultural language learning and teaching in the procedure of acquiring, processing, practicing, reflecting, and awareness-raising. This model is applicable in intercultural language learning because it highlights the active engagement of learners through social interactions and critical reflections.

IcLLT follows the five principles of IcLL of "active construction, "making "connections", "social interaction", "reflection", and "responsibility". However, to make the model fit in the context of teaching EFL to upper secondary students, modifications are made to the two steps of "social interaction" and "responsibility". First, according to Liddicoat et al. (2003) and Liddicoat and Scarino (2013), the "social interaction" involves real-life interactions across linguistic and cultural boundaries, which are not common in an FL teaching context, so the (social) "interaction" in IcLLT is meaningful interactions between teachers and students or 
among students. To ensure the authenticity of the "interaction" and stimulate students' active engagement, they could be asked to share their cultural knowledge and experiences. Second, the "extension" in the IcLLT model differs from the "responsibility" suggested by Liddicoat et al. (2003) and Liddicoat and Scarino (2013). As a principle, the "responsibility" motivates learners to engage in successful communication across languages and cultures to develop their intercultural awareness. However, it is not likely to be adopted as an intercultural teaching step or strategy in teaching EFL in general education. For that purpose, the "extension" is proposed in place for the "responsibility" as the last step of the IcLLT model. In this model, the "extension" could be conducted in the form of extramural intercultural activities to engage students in simulated or real intercultural communication: talking to guest speakers, doing problem-solving tasks, participating in role-plays, doing community-based projects related to culture, celebrating cultural events, making pen pals from other cultures, and so forth. In the five IcLLT steps of "construction", "connection", "reflection", "interaction", and "extension", learners are actively engaged in social interaction and critical reflection to foster their own IC as what is shown in Figure 2, the theoretical framework of this study.

\section{Figure 2}

IcLLT Model

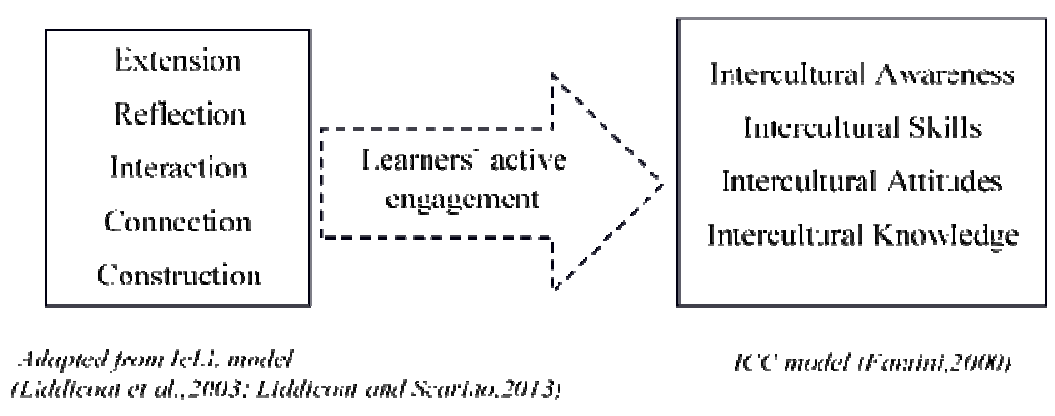

The IcLLT adopted principles for intercultural (communicative language) teaching proposed by Liddicoat and Crozet (1997), Newton et al. (2010), and Newton (2016) as guidelines for the integration of culture into EFL teaching.

- Intercultural teaching should be included in language lessons, not only a lesson 
by itself but with a balance of cultural and linguistic focus.

- Intercultural teaching integration should be both implicit and explicit with clearly stated intercultural outcomes.

- Intercultural teaching should foster learners' acquiring and learning process.

- Intercultural teaching should take the diversity of learners and contexts into account with a variety of intercultural language activities.

- Intercultural teaching should aim to develop learners' ICC rather than nativespeaker competence.

On that basis, the IcLLT suggests the two adaptions for the current CLT lessons with (1) the addition of intercultural objectives and (2) the revisions of languagebased activities towards intercultural language activities, which happen in the five stages of "construction", “connection", "reflection", "interaction", and "extension".

\subsubsection{Intercultural Objectives}

ICC objectives should be addressed in the IcLLT lessons, which is one of the distinctions between IcLLT and CLT lessons. Intercultural objectives can be segmented according to their dimensions and measured analytically (Deardorff, 2006). Besides, IC and CC should be addressed and measured separately for the practicality of measurement and conducting relevant intercultural language activities.

\subsubsection{The Suggested IcLLT Lesson Plan}

A sample of an IcLLT lesson plan, following the five-task-components structure of input, activities, goals, roles, and settings (Nunan, 1989, as cited in Corbett, 2003) and descriptions of intercultural language teaching lesson plan (see Corbett, 2003) is presented in Appendix A.

\subsection{Intercultural Language Learning and Teaching Models Implemented in Related Studies}

In tertiary informal education in Vietnam, research on integrating culture into teaching EFL explicitly to develop students' ICC has flourished. Sharing similar theoretical backgrounds with this study, also based on intercultural communicative 
language learning and teaching principles (Liddicoat, 2002; Newton et al., 2010), Ho (2011) and Tran (2015) developed models for integrating culture to language teaching to build students' ICC. It was found that the two models have received a positive evaluation from participating teachers and students. More importantly, the experimental groups of intercultural integration outweighed the intact groups in terms of IC and ICC development.

Ho's (2011) IC lessons were adapted to reflect the five IcLL principles (Liddicoat et al., 2003) of (1) active construction; (2) making connections; (3) social interaction; (4) reflection and (5) responsibility. In speaking IC lessons, role-plays and ethnographic interviews were frequently conducted to create social interaction. Role-play allows students to act out the roles of different participants in a given intercultural situation. Ethnographic interview engages students to participate in social interaction with a native English speaker invited to the classroom through an ethnographic interview. Though all the four IC elements were subjected to qualitative and quantitative measurement and the meaningful growth of students' IC and their positive perceptions of IC teaching were confirmed, Ho (2011) agreed that IC objectives can be segmented and graded according to the levels of students' acquisition and engagement into social interaction.

Tran (2015) developed ICLT model of input - notice - practice - output based on Liddicoat's (2002) model of IC acquisition with the balance and interrelationship between language and culture, which were manifested in the ICLT lesson objectives and activities. Comparing to Ho's (2011) model, the four elements made up ICLT are more explicit to describe EFL lesson stages. With regard to IC teaching strategies and goals, Tran (2015) stated that the "input" aimed for language knowledge and intercultural knowledge from exposing learners to a variety of authentic resources about different cultures; the "notice" for learners' intercultural attitudes and awareness by having learners notice and make comparisons between unfamiliar and familiar features between cultures; the "practice" for intercultural skills by engaging learners in practicing short and guided communicative tasks; and the "output" for interculture in use by creating an authentic environment to help learners build their intercultural competence in different situations.

Sharing common principles for intercultural language learning and teaching, the two models above have some differences in terms of the activities involved and the statements of intercultural objectives. Applying IcLL model, Ho (2011) specified intercultural objectives according to intercultural language activities to engage 
learners' social interaction to develop their intercultural knowledge, skills, and attitudes. Tran's (2015) ICLT model was aimed to develop learners' IC in parallel to language competencies in integrated skill lessons. The IcLLT model, proposed in this study applying IcLL as a holistic learning and teaching model with the five stages of "construction", "connection", "reflection", "interaction", and "extension" aims to build students IC explicitly besides $\mathrm{CC}$ objectives. The implementability of the five stages of IcLLT model with the recognition of IC objectives in EFL teaching in general education is the main gap this study aims to fill.

\section{Method}

This study embraces action research design applying the POAR model (Kemmis \& McTaggart, 1988) of "planning" (planning), "acting" (implementing the plan), "observing" (observing the implementation), and "reflecting" (reflecting on the implementation based on the observation). In class-based research, "acting" and "teaching" can be used alternatively; "teaching" and "observing" are concurrently reported. IcLLT model of "construction", "connection", "interaction", "reflection" and "extension" was applied to teach two integrated skill lessons, titled "Communication and Culture". Students' responses to the IcLLT lessons were reflected from written evaluation sheets, class observations, and writing tasks given as homework. The EFL teacher who taught the class as her usual business was invited to join all steps of the research cycle and gave her evaluation of the implementation. Additionally, a Canadian teacher, who is also a writer, was invited as a guest speaker to give a lecture on a related intercultural issue.

\section{Results}

This part presents the application of the IcLLT model to exploit two "Communication and Culture" lessons in Unit 6 and 7 of the pilot coursebook grade 10.

\subsection{Planning}

The participating teacher and the researcher agreed that the planning of IcLLT lessons should respect the provided language and culture content and language 
objectives. Besides, the active engagement of the students should be the main criterion to design intercultural language activities. Two IcLLT lesson plans of Unit 6 and Unit 7 are presented in Appendix B and C respectively. Most of the adjustments are aimed to enhance social interactions and critical reflections toward intercultural issues among the students. To clarify, most of the language and culture content remained unchanged in the two lessons, but the nature of tasks in terms of the authenticity of the interactions, the depth and criticality of the discussion, and the use of students' prior knowledge and experience were paid with more special attention.

\subsection{Teaching and Observing}

This part presents how the two IcLLT lessons happened, focusing on the process of class activities (intercultural language activities) in the five steps and the product of the students' use of language and IC from the observations and their written works.

\subsubsection{Construction}

The "construction" could partly achieve its aim in activating the students' prior knowledge about the set topic. From observations, the students' participation in the "construction" of Unit 6 was less obvious than those of Unit 7. In Unit 6, the addition of the "construction" as pre-speaking activity and pre-reading activity was relevant, but the students' engagement was not apparent. In the "construction" of the Culture section (Appendix B), the students were eager to report how they envisioned their future success (see Excerpt 1).

\section{Excerpt 1: Samples of students' interaction}

C7: "I don't care much about my job... just help me to earn enough for my life. I want to have a good husband with many children. That is more important to me."

F7: "All what I want is to have a shop to sell accessories to teenagers. I won't go to university."

G7: "I will have a good job and earn a lot of money for my parents. I will be a good wife to my husband."

\subsubsection{Connection}

The "connection" was a compulsory part of the IcLLT model. In Unit 6, the "connection" and the "interaction" were merged into one activity, in which the students interact with their peers to compare cultural practices (from the provided 
reading texts) and the students' prior knowledge. A better way to combine the comparison and interaction about culture was having the students record the compared details in a grid and engaging them in a discussion about it (see Handout, Unit 7, Appendix C).

\subsubsection{Interaction}

Intercultural language activities involved the engagement and language productivity of the students at different levels in both two lessons. The observations showed that the students made a "noisy crowd" when they talked about what they had known and experienced. For example, in Unit 6, the students were able to use their own words to talk about the achievements in "gender equality" in Vietnam (see Excerpt 2).

\section{Excerpt 2: Samples of students' interaction}

A6. "In the past, women have no or less education than men ... but now, women have more than men."

C6. "Women were caregivers and housewives. Now, they can follow their dreams and do their favourite jobs."

H6. "Even women can join the army to become a soldier."

Similarly, students were excited and well engaged in interaction due to the familiarity of the topic. As shown in Excerpt 3, their language choice and production were various and natural.

\section{Excerpt 3: A sample of students' conversation}

A7: "Who do you often buy presents for?"

C7: "Erh, ... me? I never buy any presents. I don't have money."

A7: "Ah, OK! What is the most expensive present you have been given?"

C7: "I don't know because I don't care how much it is. I never look a gift horse in the mouth ..."

\subsubsection{Reflection}

Students' language productivity was not obviously seen in some part of the discussion of reflective questions. However, the evidence of students' engagement in the "reflection" was more visible in their writing assignments on "gender equality" and "values of success". In fact, the students' written reflections (in Unit 
6) were based on what they experienced and thought rather than what they learned from the culture input presented in the coursebook (see Task 4, Culture, Unit 6, Appendix B). The students were taught about gender achievements in Vietnam, but they raised many issues about gender bias (see Excerpt 4), such as child gender preference, social gender expectations, schooling opportunities, domestic violence, and household workload.

Excerpt 4: Students' reflections on gender issue in Vietnam

Question: Do you think that in Vietnam, women are equal to men? Why (not)?

A6: "No, I don't think that men and women are equal. Baby boys are more preferable than girls."

C6: "No, people usually say you are girls, do this or don't do that even people who have the same gender as me. Why so?"

D6: "No, because too many girls cannot go to schools or universities."

F6: "No, every day, domestic violence still happens. Very often, women are victims."

P6: "No, I don't think so. In my family, my dad has nothing to do at home besides playing games and watching TV while my mom is busy doing a lot of things."

Similarly, in Unit 7, the students could express meanings of success from the views of different generations. As shown in Excerpt 5, the success that the students pursued was diverse and radical while their parents' expectations were rather conventional: practical and even materialistic.

Excerpt 5: Students' versus their parents' perspectives on success

A7: "To my parents, I should study well in Math, Physics, and Chemistry, make a lot of money, have a good job and a big house, and have beautiful children, ... All I need is a job to make enough money from my passion, have true friends, have time to enjoy my life."

C7: "My parents expect me to be a successful person with a stable income, happy family with good children and good husband". But, I hope to become a single mom with a little daughter, without a husband".

D7: "They also hope my career has not much hardship. But I like adventures. I want to experience new things and challenge in society confidently." 
The students' written assignments showed that they were able to express their own perspectives towards certain intercultural issues. This fact reassured students' capacity to perform reflective tasks in terms of language productivity and critical thinking ability when they had enough time for preparation.

\subsubsection{Extension}

Together with students from other classes and teachers in the school, 15 of the 23 students in the class attended a lecture in English about cross-cultural meanings of femininity in story-telling through different versions of Cinderella, given by a Canadian guest speaker. The students were provided with different versions of Cinderella from the US., Germany, France, and Vietnam and encouraged exchange their perspectives about femininity across cultures (see Excerpt 6).

\section{Excerpt 6: Extracts of students' writing}

J6: "Femininity was not connected to bad things in many cultures. For example, bad people with cruel conduct were women like the stepmother and stepsister. People of power and nobility were often males like the King and the father."

K6: "Women were loved and wanted for different reasons. Cinderella in Western cultures dressed charmingly and danced beautifully to entice the Prince. In Vietnamese legend, Tam was noticed and wanted for being at working, farming, and keeping the house."

As what was shown from the observations and the students' writings, it was confirmed that the students could be actively engaged in the IcLLT activities and able to use English effectively to express their critical thoughts.

\subsection{Reflecting}

Students' and teacher's responses to the IcLLT lessons were reflected from the students' evaluation sheets and the teacher interview.

All of the students gave positive responses to the IcLLT lessons in terms of structures, activities, and intercultural content. As further explanation, they appreciated language and culture input because interesting cultural topics encouraged them to study more vocabulary and practice language skills better. They were more interested in intercultural activities to foster IC at higher levels, namely 
stating their opinions, talking to foreigners, and discussing intercultural issues.

In the teacher interview for her reflection on the implementation of the IcLLT model, she approved the integration of culture into teaching and briefly described how she would apply the IcLLT model in her teaching. The "connection" could be applied due to the representation of culture-specific in the coursebook. If the comparison was made based on the provided input, it was the "connection". If the provided cultural input was compared with and reflected on the students' own cultural experiences, it could be the "interaction" or the "reflection". The distinction between those two steps depended on the depth of discussion. If the gap was attributed to the students' knowledge and experience, it could be the "interaction". If it was their attitude and opinion, it should be the "reflection". Of the three steps, the "reflection" concerned her most because the students' language productivity in this step was not proven in classroom interaction but delayed in written assignments. That was why the feasibility of this step was not convincing enough to her. Also, the "construction" and "extension" were applicable as long as she had enough time. Surprisingly, she was quite confident with the "extension" because it could be a part of the lesson entitled "Project", a succeeding section of the "Communication and Culture", or added in the periodical extracurricular activity of the school.

From the student's and teachers' evaluations, it was proven that the "Communication and Culture" lessons could be conducted according to the five steps of IcLLT model and the intercultural language activities engaged the students' active participation in social interaction and critical reflection.

\section{Discussion and Implications}

The teacher's and students' responses to the implementation of IcLLT lessons are discussed with two foci: (1) the compatibility of the IcLLT model to EFL lessons in the pilot coursebooks and (2) implications for cultivating IC in EFL teaching.

The implementation proves that IcLLT is an open and flexible model that could be varied to different EFL teaching contexts. As shown in the trial lessons, one step could be skipped and included in another. The "construction" and the "connection", the "connection" and the "interaction", or the "interaction" and the "reflection" could be embedded in each other in one or two related intercultural language activities. Of the five steps, the "construction", the "connection", and the 
"interaction" are common parts of language lessons, which can be exploited in parallel with CLT three-staged receptive skill lessons of Pre-While-Post. The "reflection" and the "extension" were almost ignored due to the requirement of elaborate preparations. Though steps could be missed or merged with the others; the order of IcLLT steps should be observed according to the development of students' active engagement, independent use of language, and levels of cognition required.

Comparing to the implementation of IcLL (Ho, 2011) and ICLT model (Tran, 2015), the growth of the students' IC and CC in the IcLLT were not confirmed due to the differences in the research participants, designs, objectives, and the rigidity of the curriculum. However, all three models aim to integrate culture into teaching EFL skill lessons to foster learners' ICC through the implementation of intercultural language activities to engage the students' active involvement in social interactions and critical reflections towards intercultural issues. Reviewing the two suggested activities in the IcLL model (Ho, 2011), role-plays and ethnographic interviews could be conducted in the "extension", which could be a part of the Project section or extra-curricular activity as the participating teacher suggested. Compared to the IcLL model (Ho, 2011), the ICLT (Tran, 2015) was more relevant to the IcLLT with the progressive and chronological procedure of explicit strategies for intercultural language activities in each step. To further explain, the model of input notice - practice - output was similar to construction - connection - interaction extension. The presence of the "reflection" in the IcLLT model is not redundant but attributed to the learner difference. As the explanation of the participating teacher, the difference between the "interaction" and "reflection" relies on the depth of the discussion, to what degree the students reflect on certain intercultural issues from their own perspectives. It is noticeable that all three models allowed the students more freedom of language use and IC building, which are apt to the new objectives of the overall English teaching curriculum (MOET, 2018).

To cultivate IC in EFL classrooms, the simplicity and familiarity of the tasks and intercultural input should be considered. First, simplicity is the key to activate all students in mixed-ability classes. Taking the proposed intercultural language activities in the two demo lessons as examples, the activities were graded to engage the students of different levels of language proficiency and cognition ability. Second, the familiarity of the intercultural topics to the students' prior knowledge and experience is a supportive factor to the students' participation and language use 
(Carlson, 2019; Ho, 2011). It was also evidenced by the active participation of the students in the discussion to reflect on their perspectives and experiences about gender (in)equality and the value of success (in Unit 6 and 7 respectively) as cultural informants.

Another way to cultivate IC was creating genuine social interactions among different individuals. One of the easiest and most effective ways to practice intercultural teaching is to start with themselves and close to their own real-life experience (Ho, 2011; Newton, 2016). Though living in the same community, learners themselves have different backgrounds, personal experiences, attitudes, and perspectives. The gaps among learners can be considered as information and opinion gaps, which create authentic needs for communication in the "interaction", the "reflection", and the "extension". Moreover, the learners' different perspectives toward certain issues could be great sources to exploit the intercultural input in the pilot coursebooks. Though there is not enough evidence to conclude that the cultural input was "rosy", safe, and national-culture biased but the presence of "gender achievements" in Vietnam and "gender inequality" in the UK (Unit 6, Appendix B) is an example of avoidance of relating social problems in Vietnam. In this line, Le (2018) confirmed that the pilot EFL coursebooks ignored the dark sides of contemporary society locally and globally, namely academic misbehaviours, family violence, corruption, dishonesty, drug, terrorism, poverty, and many other issues. Without mentioning social reality in language and cultural input, the coursebooks miss opportunities to invoke students' critical discussions (Rashidi \& Sarifi, as cited in Le, 2018). To complement the lack of social reality in the coursebook content, teachers can conduct intercultural language activities to encourage students to add the truth that they can see, know, and think of the learned topics as part of their own social and cultural experiences.

As stated, there exists a gap between the objectives of the general curriculum for teaching EFL and its implementation at the grass-root level (Chau \& Truong, 2018). The change of coursebooks with a variety of culture-specific input is not enough to ensure the success of teachers' practice of integrating culture for the attainment of the students' IC or ICC. To fill the gap, the application of the IcLLT model with adapted intercultural language activities should be recommended. However, to guide the teachers in lesson planning and designing appropriate IcLLT activities, it is necessary to add intercultural objectives in tandem with language objectives. As in the implementation, the IcLLT applied in teaching EFL education aims to build 
learners' intercultural knowledge, attitudes, and skills. The separation and limitation of IC objectives suggested in this research is relevant to the specification and measurement of IC objectives (Deardorff, 2006) and IC developmental patterns (Liddicoat et al., 2003). In a similar empirical study, Ho (2011) chose two IC dimensions: intercultural attitude and intercultural awareness as intercultural goals of intercultural lesson plans because obtaining all components of IC in a short treatment is vulnerable. Finally, it is not necessary to cover all three suggested dimensions of IC in a single lesson. Nonetheless, building intercultural knowledge alone is not a perfect statement of intercultural objectives because intercultural knowledge itself is just a basic level of IC and cannot automatically lead to the formation of more comprehensive levels, such as intercultural attitude and intercultural skill. Possessing intercultural knowledge is a prerequisite for building those competences. Depending on the nature of intercultural input, teachers can design appropriate intercultural language activities to help students to achieve intercultural attitudes and skills besides intercultural knowledge.

As presented above, the suggested intercultural language activities to integrate culture into teaching EFL are familiar and feasible. However, to apply the model, besides the implementation of the new coursebooks, teachers should be guided with intercultural teaching pedagogy, so that they could design appropriate intercultural language activities based on the provided activities in the coursebooks and propose relevant intercultural objectives. Hence, they can help students to be confidently engaged in intercultural communication and responsible for their critical judgments, which contributes to form CC and "intercultural citizenship" (Byram, 2008, pp. 1112).

\section{Limitation and Conclusion}

Besides the findings and pedagogical implications for the practice of intercultural integration that this study has covered, it has considerable limitations. First, the action research design experimenting with the IcLLT model in two EFL lessons is assailable because it was not long or comprehensive enough for the researcher to get insights into the drawbacks and benefits of the model. Second, IcLLT may be an open and weak model, which has been tested in limited lessons, curriculum, and participants. Only some activities were chosen based on the availability and 
accessibility of the resources, not for the sake of generalizability. Third, the suggested intercultural language teaching activities in the trial IcLLT lessons were not likely suitable to teach complete beginners or children. Forth, the suggested intercultural language activities were not specially designed to teach culture-inlanguage obviously and properly. For those reasons, it is suggested that more research should be done to make the model more applicable and comprehensive.

In conclusion, this research is a trial implementation of the IcLLT model to exploit specific cultural input provided in the coursebook to foster the students' IC and $\mathrm{CC}$ through intercultural language activities. Though the model is progressing and chronological, it can be split into individual steps that are relevant to CLT receptive skill lessons. The achievement of the model is proved by the active engagement of the students in genuine social interactions and critical reflections to develop their IC besides CC. Proven in the research, the teachers and students agreed that the IcLLT was implementable, its implementability varied according to the nature and diversity of intercultural content prescribed in the coursebooks. Hence, with the synergy of educational reforms from central management and the adjustment of teachers' instructions, the IcLLT could be a supplementary approach to include culture in EFL education to foster students' ICC. 


\section{References}

Browett, J. (2003). Culture: Are we speaking the same language? Teachers'conceptual frameworks of culture. Babel, 38(2), 18-25.

Byram, M. (1997). Teaching and assessing intercultural communicative competence. Multilingual Matters.

Byram, M. (2008). From foreign language education to education for intercultural citizenship. Multilingual Matters.

Byram, M., Gribkova, B., \& Starkey, H. (2002). Developing the intercultural dimension in language teaching: A practical introduction for teachers. Council of Europe.

Chau, T. T. H. \& Truong, V. (2018). Integrating cultures into teaching EFL in Vietnam: Teachers' perceptions. LEARN Journal, 11(2), 103-115.

Chau, T. H. H., \& Truong, V. (2019). The integration of intercultural education into teaching English: What Vietnamese teachers do and say. International Journal of Instruction, 12(1), 441-456. https://doi.org/10.29333/iji.2019.12129a

Carlson, G. (2019). Listening comprehension through culturally familiar contexts: A case study in Japan. PASAA - A Journal of Language Teaching and Learning, $58,39-59$.

Crozet, C. Liddicoat, A. J. \& Lo Bianco, J. (1999). Intercultural competence: From language policy to language education. In J. Lo Bianco, A. J. Liddicoat and C. Crozet (Eds.), Striving for the third place: Intercultural competence through language education (pp. 1-20). Language Australia.

Deardorff, D. K. (2006). The identification and assessment of intercultural competence as a student outcome of internationalization. Journal of Studies in International Education, 10(3), 241-266.

Dinh, N. T. (2016). Culture representations in English language teaching curriculum in Vietnam. [Electronic doctoral dissertation]. Monash University.

Fantini, A. (2000). A central concern: Developing intercultural competence. SIT Occasional Papers Series: Addressing Intercultural Education, Training and Service, 25-33. School for International Training. http://www.sit.edu/ SITOccasionalPapers/sitops01.pdf 
Fantini, A. E. (2006). Exploring and assessing intercultural competence. World Learning Publications. http://www.sit.edu/publications/docs/feil_research_report. pdf

Fantini, A. E., Arias-Galicia, F., \& Guay, D. (2001). Globalization and 21 st century competencies: Challenges for North American higher education. Western Interstate Commission on Higher Education.

Ho, S. T. K. (2011). An investigation of intercultural teaching and learning in tertiary EFL classrooms in Vietnam. [Electronic doctoral dissertation]. Victoria University of Wellington.

Hoang, V. V. (2016). Renovation in curriculum design and textbook development: an effective solution to improving the quality of English teaching in Vietnamese schools in the context of integration and globalization. VNU Journal of Science: Education Research, 32(4), 9-20. DOI:10.25073/2588-1159/vnuer.3845

Hoang, V. V. (2018). MOET's three pilot English language communicational curricula for schools in Vietnam: rationale, design and implementation. Tap chí Nghiên cưu Nước ngoài, 34 (2), 1-25. DOI:10.25073/2525-2445/vnufs.4258

Kemmis, S. \& McTaggart R. (1988). The action research planner. Deakin University Press.

Lai, T. T. V. (2016). An evaluation of textbook English 10 - Volume 1 (experimental program) developed by Vietnamese Ministry of Education and Training as seen from intercultural communicative EFL approach. Researching and Teaching Foreign Languages, Linguistics, Foreign Studies in Vietnam, National Conference 2016, Ha Noi, Vietnam,

Le V. C. (2018). A critical analysis of moral values in Vietnam-produced EFL textbooks for upper secondary schools. In Widodo, H. P., Perfecto, M. R., Canh, L. V., Buripakdi, A, (Eds.), Situating Moral and Cultural Values in ELT Materials - The South East Asian Context (pp. 111-129). Springer.

Liddicoat, A. J. (1997). Everyday speech as culture: Implications for language teaching. In A. J. Liddicoat \& C. Crozet (Eds.), Teaching Language, Teaching Culture (pp. 55-70). Applied Linguistics Association of Australia.

Liddicoat, A. J. (2002). Static and dynamic views of culture and intercultural language acquisition. Babel, 36(3), 4-11. 
Liddicoat, A. J., \& Crozet, C. (1997). Teaching language, teaching culture.: Applied Linguistics Association of Australia.

Liddicoat, A. J. \& Scarino, A. (2013). Intercultural language teaching and learning. Wiley-Blackwell.

Liddicoat, A. J., Papademetre, L., Scarino, A., \& Kohler, M. (2003). Report on intercultural language learning. Canberra, ACT: Commonwealth of Australia.

MOET (2012). The pilot curriculum for teaching English in general education. Decision 5209/QĐ-BGDĐT. https://thuvienphapluat.vn/van-ban/giaoduc/Quyet-dinh-5209-QD-BGDDT-nam-2012-Chuong-trinh-giao-duc-phothong-mon-tieng-Anh-180993.aspx

MOET (2018). The new overall curriculum in EFL in upper secondary education. Circular 32/2018/TT-BGDĐT. https://thuvienphapluat.vn/van-ban/giaoduc/Thong-tu-32-2018-TT-BGDDT-Chuong-trinh-giao-duc-pho-thong403454.aspx

Newton, J. (2016). Cultivating intercultural competence in tertiary EFL programs. Crossing Borders in Language Teaching and Business Communication: Proceedings of the 11th ELT conference at AE Chaoyang University of Technology, 1-22.

Newton, J., Yates, E., Shearn, S. \& Nowitzki, W. (2010). Intercultural communicative language teaching: Implications for effective teaching and learning. Ministry of Education.

Paige, R. M., Jorstad, H., Siaya, L., Klein, F., \& Colby, J. (2003). Culture learning in language education: A review of the literature. In D. L. Lange \& R. M. Paige (Eds.), Culture as the core: Perspectives on culture in second language learning (pp. 173-236). Information Age Building.

Sewell, W. H. (2005). Logics of history: Social theory and social transformation. University of Chicago Press.

Tran, Q. T. (2015). An intercultural communicative language teaching model for EFL learners. [Electronic Doctoral dissertation]. Suranaree University of Technology.

Vygotsky, L. S. (1978). Mind in society: The development of higher psychological processes. Harvard University Press. 


\section{Bionote}

${ }^{1}$ Chau Thi Hoang Hoa, PhD. is an EFL teacher at Tra Vinh University, Vietnam. Her research interests are teaching EFF in general education, teacher education, and integrating cultures into teaching EFF. She is especially interested in studying a diversity of strategies to integrate culture into teaching EFL in upper secondary education in Vietnam to build learners' intercultural communicative competence.

\section{Appendices}

Appendix A. A Suggested IcLLT Lesson Plan

\begin{tabular}{|c|c|}
\hline Elements & Descriptions \\
\hline Approach & $\begin{array}{l}\text { - CLT/ Communicative Approach } \\
\text { - Supplemented with IcLLT approach }\end{array}$ \\
\hline Objectives & $\begin{array}{l}\text { - Language objectives } \\
\text { - IC objectives of intercultural knowledge, attitudes, and skills }\end{array}$ \\
\hline Input & $\begin{array}{l}\text { - Language and culture-specific } \\
\text { - From the coursebook and teacher } \\
\text { - From the learners and the local community }\end{array}$ \\
\hline Tasks & Intercultural language activities \\
\hline $\begin{array}{l}\text { Stages of the } \\
\text { lesson and } \\
\text { activities }\end{array}$ & $\begin{array}{l}\text { Construction } \\
\text { Building and exploring intercultural issues base on prior intercultural } \\
\text { knowledge and experience. } \\
\text { Connection } \\
\text { Making (implicit/explicit) comparison/ connection between home culture } \\
\text { and other cultures } \\
\text { Interaction } \\
\text { Engaging in genuine interactions about intercultural issues to practice } \\
\text { language skills and construct cultural meanings. }\end{array}$ \\
\hline
\end{tabular}




\begin{tabular}{|l|l|}
\hline & $\begin{array}{l}\text { Reflection } \\
\text { Reflecting/giving their own feedback on intercultural issues to build their } \\
\text { intercultural attitudes } \\
\text { Extension } \\
\text { Participating in real or simulated intercultural communication to build } \\
\text { ICC focusing on intercultural skills. }\end{array}$ \\
\hline Setting & $\begin{array}{l}\text { In and out of the classroom, through intra - and extracurricular activities, } \\
\text { focusing on community engagement. }\end{array}$ \\
\hline
\end{tabular}

\section{Appendix B. IcLLT Lesson Plan for Communication and Culture: Trial lesson 1}

(Unit 6, p.13, English 10, the pilot coursebook)

\section{Language Objective}

- to build language skills (reading and speaking) about gender (in)equality

\section{IC Objectives}

- to build students' knowledge and attitudes towards the issue of gender (in)equality (Vietnam, the UK, and other countries)

- to build students' own perspectives on gender equality

\section{COMMUNICATION}

Task 1: Construction: Read three statements about achievements in woman equality to match with the pictures and then add other ideas from students' knowledge and opinions.

\section{Task 2: Connection/Interaction}

Exchange ideas in pairs

\section{CULTURE}

\section{Task 1: Construction}

Read the given text about Gender equality in the UK, and do comprehension questions (p.13).

1. How do girls and boys perform at schools in the United Kingdom? 
2. How many women participate in the British workforce?

3. What challenges does the United Kingdom still face in achieving gender equality?

\section{Task 2: Connection - Interaction}

Compare facts of gender inequality in the UK (in the text) and those in Vietnam (from students' knowledge and experience)

\section{Task 3: Reflection}

Discuss the following questions

1. Compare to the UK and Canada, how do you think of gender equality in Vietnam?

2. What are the roots of gender inequality?

3. What can we do to reduce gender inequality?

Language use: I think/I guess/ I suppose that....

\section{Homework:}

(*) In about 30 words, state that in Vietnam, are women equal to men? Why (not)?

\section{Extension (optional)}

- Attend a guest speaker's talk on cross-cultural meanings of femininity in story-telling through different versions of Cinderella and write a report/an essay on it.

- Share your writing/view with your friends (and if possible, keep it posted on a social network to call for further discussion). 
Integrating Culture into Teaching ...

Appendix C. IcLLT Lesson Plan for Communication and Culture: Trial Lesson 2

(Unit 7, p. 23, Tieng Anh 10, the pilot coursebook)

\section{Language Objective:}

- to read and talk about common cultural issues of gift-giving and the value of success

\section{IC Objectives:}

- to share knowledge and experience about the practices of gift-giving in Vietnam and the UK

- to build students' perceptive/ values of their own success from the views of American, Vietnamese cultures

\section{COMMUNICATION}

\section{Task 1: Construction and connection}

Read the given passage about gift-giving in the UK (p. 23)

Fill in the table (handout, unit 7)

\section{Task 2: Interaction 1}

Share information from the table

Language Focus:

Do you get presents on

No, I don't. (explanations)

Really? / Exclamations

\section{Task 3: Interaction 2}

Ask and answer in pairs:

1. Who do you often buy presents for?

2. On what occasions do you buy presents?

3. What is the most expensive present you have been given? 
4. On what occasions do you receive presents?

5. What presents do you normally get?

7. What is the best present you have ever received?

\section{CULTURE}

\section{Task 1: Construction}

Describe a successful person/ how you want to lead your life as a successful person.

Draw a picture of Mr./Ms. Success that the students could figure out, then pair compare.

\section{Task 2: Connection and interaction}

Read the given passages about the value of success in American and Vietnamese culture (p. 24); then answer the provided comprehension questions.

\section{Task 3: Reflection}

Check your Mr. /Ms. Success. (if it is more American or more Vietnamese?)

Homework: Write a paragraph to answer the following questions.

- How to be a successful person as your parents expect?

- How to be a successful person as you expect?

- Are there any conflicts between the two generations' expectations?

- What do you do to achieve such success? 